\title{
Monitoring of Health and Demographic Outcomes in Poor Urban Settlements: Evidence from the Nairobi Urban Health and Demographic Surveillance System
}

\author{
Jacques Emina, Donatien Beguy, Eliya M. Zulu, Alex C. Ezeh, \\ Kanyiva Muindi, Patricia Elung'ata, John K. Otsola, \\ and Yazoumé Yé
}

\begin{abstract}
The Nairobi Urban Health and Demographic Surveillance System (NUHDSS) was set up in Korogocho and Viwandani slum settlements to provide a platform for investigating linkages between urban poverty, health, and demographic and other socioeconomic outcomes, and to facilitate the evaluation of interventions to improve the wellbeing of the urban poor. Data from the NUHDSS confirm the high level of population mobility in slum settlements, and also demonstrate that slum settlements are long-term homes for many people. Research and intervention programs should take account of the duality of slum residency. Consistent with the trends observed countrywide, the data show substantial improvements in measures of child mortality, while there has been limited decline in fertility in slum settlements. The NUHDSS experience has shown that it is feasible to set up and implement long-term health and demographic surveillance system in urban slum settlements and to generate vital data for guiding policy and actions aimed at improving the wellbeing of the urban poor.
\end{abstract}

KEYWORDS Urban slum, Health and demographic surveillance system, Health and demographic indicators, Korogocho, Viwandani, Nairobi, Kenya.

\section{BACKGROUND}

Africa's capacity to closely monitor key demographic events is curtailed by lack of vital registration systems, which would help account for all births, deaths, and population movements. Understanding patterns, spatial dimensions, and trends in these key demographic events would be very vital for the planning of health, social, and related services. Population-based Health and Demographic Surveillance Systems (HDSSs) were designed to fill this important data gap. The HDSS involves the prospective followup on a well-defined population living in a clearly circumscribed geographic area. ${ }^{1}$ The HDSS records and monitors changes in vital health and demographic events relating to the population under surveillance. In addition to collecting these health and

Zulu is with the African Institute for Development Policy (AFIDEP), Nairobi, Kenya; Emina, Beguy, Ezeh, Muindi, and Elung'ata are with the African Population and Health Research Center (APHRC), Nairobi, Kenya; Otsola is with the United States International University, Nairobi, Kenya; Yé is with the ICF Macro, Calverton, MD, USA.

Correspondence: Jacques Emina and Donatien Beguy, African Population and Health Research Center (APHRC), Shelter Afrique Center, Longonot Road, Nairobo, Kenya. (E-mail: jacques.emina@gmail.com; E-mail: dbeguy@aphrc.org) 
demographic data, HDSSs also provide broader platforms for conducting nested research studies, including clinical trials and behavioral studies. In fact, many HDSSs have evolved out of clinical and behavioral research projects that sought to follow up people for a few years and then decided on a full demographic surveillance. The information collected often vary across the HDSS sites and depends on the research focus of a site. However, the minimum data recorded by all HDSS sites include vital events (births and deaths) and in-migrations and out-migrations. These variables capture changes in the population under surveillance and provide an appropriate denominator for calculating rates.

The first HDSS in Africa was located at the Pholela Health Centre in South Africa, which started in 1940. The project was established by the South African Ministry of Health as a Community Oriented Primary Health Care initiative to prevent and treat diseases prevalent in rural Natal (such as tuberculosis, syphilis, smallpox, typhoid, and measles), and to inform health policy. ${ }^{2,3}$ Niakhar, the second site in rural Senegal, was created in 1962 under the Niakhar Project. This site was set up to assess the feasibility of a civil registration system in Senegal soon after its independence and to obtain reliable demographic and epidemiological data on the country's rural population ${ }^{4}$. The Nairobi Urban HDSS (NUHDSS) was the pioneer urban-based HDSS. It was set up to fill the big evidence gap in understanding the implications of rapid urbanization and the rapidly growing concentration of poverty and ill health in slum settlements in Africa's major cities. The site was set up by the African Population and Health Research Center in two slum settlements (Korogocho and Viwandani) in 2002. The main objective of the site was to provide a longitudinal platform for investigating linkages between urban poverty and wellbeing outcomes including health, demographic, and schooling. The NUHDSS also provides a platform for evaluation of interventions aimed at improving the wellbeing of the urban poor. The routine NUHDSS data have been analyzed and its longitudinal platform used to set up nested studies for the Urbanization, Poverty and Health Dynamics (UPHD) research program whose findings are presented in the present volume.

The NUHDSS is a member of the International Network for the Demographic Evaluation of Populations and Their Health in Developing Countries (INDEPTH), which was established in 1998 to support and strengthen the ability of its member HDSS sites to conduct prospective longitudinal studies and standardize surveillance methodologies and procedures. ${ }^{5}$ INDEPTH also facilitates the translation of its findings in order to maximize the impact of its research on policy and practice. The network currently has 42 member sites located in 19 countries mostly in Africa, Asia, and Oceania. Of these 42 HDSSs, 29 are in located in 11 African countries and all but two are located in rural settings. These sites have provided valuable clinical and behavioral research evidence that has informed policies and programs for improving health care systems in the countries where the HDSSs are located and beyond.

\section{KEY HDSS CONCEPTS AND METHODS}

The HDSS is a methodological approach to monitoring demographic and health outcomes in a registered and defined population living in a circumscribed geographic area. ${ }^{1}$ The information collected at a minimum include vital events (births and deaths) and in- and out-migration. These demographic indicators are critical in accounting for the resident population of the HDSS site at any time during the follow-up. Unlike pure cohort studies, therefore, the HDSS sites adopt the concept of an open cohort that allows new members to join and existing members to leave and return to the system, 
as long as they are regular residents in the clearly defined geographic area under surveillance, often referred to as the Demographic Surveillance Area (DSA). ${ }^{1}$ The HDSS starts with an initial census of the population living in the defined geographical areas, followed by regular visits to update information on births, deaths, and migration. After the initial census, one can only become an HDSS member through birth to a registered member or through in-migration, and one can cease being a member either through death or through out-migration as depicted in Figure 1.

Depending on the key research questions that an HDSS site is addressing, various sites also monitor other key health, socio-economic, and behavioral outcomes such as vaccination status, HIV prevalence, morbidity, causes of death, marital status, schooling, employment status, and housing conditions. In some sites, the community-based data collected through the HDSS are linked to clinical data from health facilities. This arrangement not only facilitates follow-up with patients to understand what happens to them after receiving certain types of treatment, but also enriches the health data collected in communities with biomarkers that may be collected in health facilities. Some HDSS sites are linked to data collected from hospitals. By monitoring new health threats, tracking drivers of population change, and measuring the effect of policy and program interventions on communities, HDSSs equip policy makers with the valuable, long-term evidence that they need to make decisions on development and health priorities and determine cost-effective interventions that can be scaled up to improve the wellbeing of broader populations.

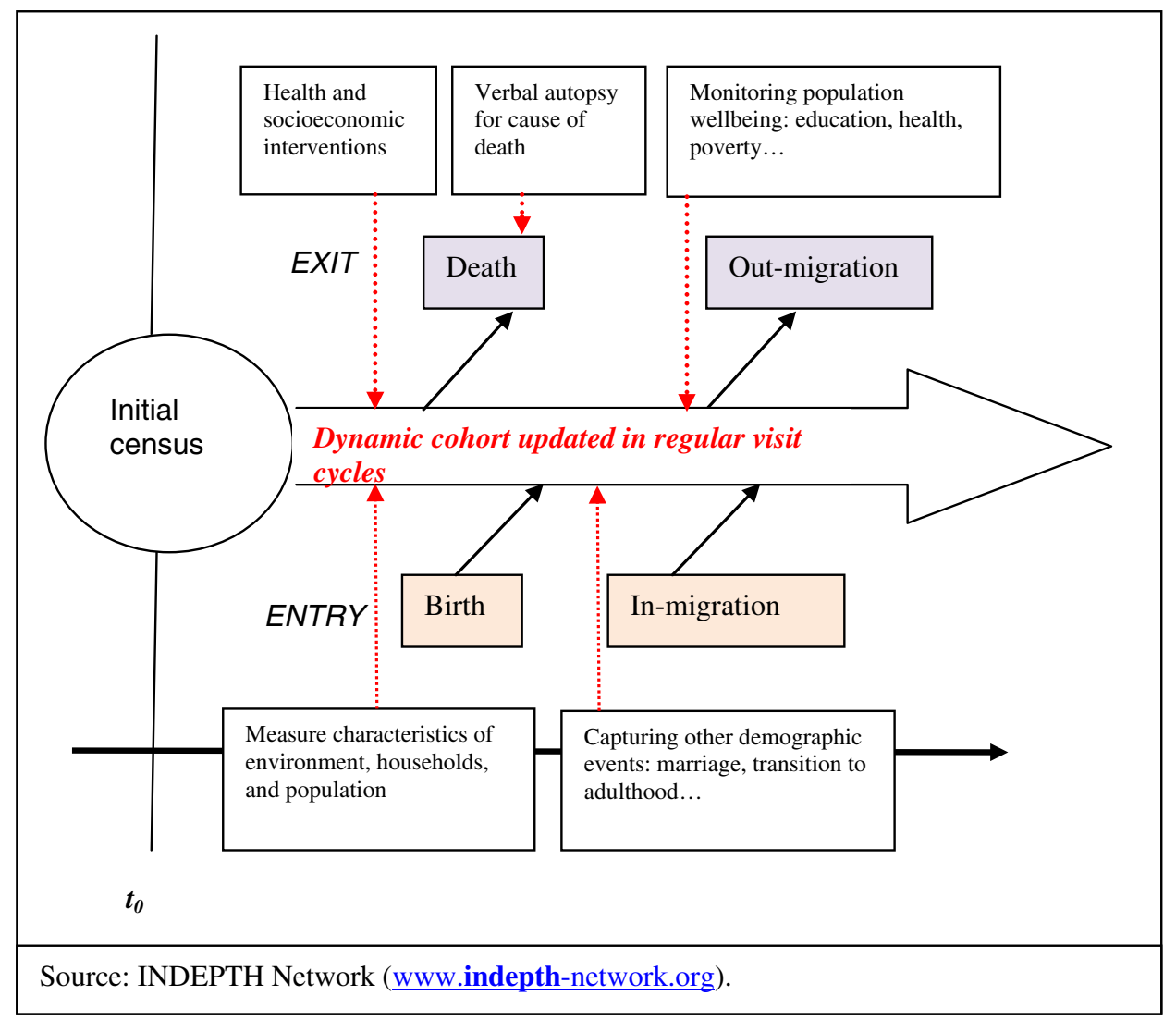

FIGURE 1. The concept of the Health and Demographic Surveillance System. 
The most obvious limitation of HDSSs is that they typically cover small geographical areas that may not be representative of key population and health characteristics that national level policy makers seek to address. In countries that have multiple HDSS sites, this problem can be minimized by pooling data from all HDSS sites to provide more comprehensive data to national policy makers. This model has worked very well in Tanzania where the country's three HDSS sites have pooled their methodologies, data, and lessons to develop resource-allocation tools based on disease-burden profiles generated from the HDSSs. ${ }^{6}$ But carefully designed interventions based on research in specific HDSS sites have also shaped national and international thinking, policies, and programs on key health issues such as diarrhea treatment in Matlab, Bangladesh ${ }^{7}$ and the use of a community health nurse to improve maternal health outcomes in Navrongo, Ghana. ${ }^{8}$

\section{THE DESIGN AND PROCEDURES FOR THE NUHDSS}

\section{Procedures of the NUHDSS}

As noted above, the NUHDSS was set up in order to provide data and a research platform for investigating changing linkages between urbanization, poverty, and health and as a tool for monitoring and evaluating the impact of the various interventions on health outcomes among urban poor in Nairobi. Given the United Nations' estimates that the majority of Africans will live in urban areas starting in $2035^{9}$ and that a significant proportion of these residents will live in slum settlements ${ }^{10}$, there was urgent need for comprehensive research evidence to help policy makers understand possibilities of intervention to improve the lives of the urban poor.

The NUHDSS was piloted in four slum settlements in Nairobi city between 2000 and 2002. The baseline census that defined the initial population for the NUHDSS was carried out in July-August 2002. Subsequent visits were made every 4 months by fieldworkers to all residential housing units and households in the DSA, which are marked with unique identification numbers to collect information on pregnancies and pregnancy outcomes, migration, episodes of morbidity, health-seeking behavior, births, mortality and causes of death, livelihood sources, vaccination coverage, marital status, and school attendance. Information on household characteristics and livelihoods are collected once a year (see Table A1 and A2 in Appendix for details). The NUHDSS has been granted ethical clearance by the Ethical Review Board of the Kenya Medical Research Institute (KEMRI).

Figure 2 shows the location of the two slum settlements where the NUHDSS is being implemented. The DSA (combining Viwandani and Korogocho slum settlements) covers a land area of about $0.97 \mathrm{~km}^{2}$, with the two informal settlements located about $7 \mathrm{~km}$ from each other. Korogocho is located $12 \mathrm{~km}$ from the city center; in Kasarani division (now Kasarani district) and has seven villages and 102 census enumeration areas. In Korogocho, most houses are made of mud and timber walls with waste tin cans as roofing materials. Houses are built in rows with an average of six dwelling units (rooms) per structure. Korogocho is one of the most congested slum areas of Nairobi with over 250 dwelling units per hectare. The Nairobi Refuse Dump site is situated to the east and south east of the slum settlement. Viwandani is $7 \mathrm{~km}$ from Nairobi city center, is located in Makadara division (now Madaraka district), and has seven villages and 34 censusenumeration areas. Most structures in Viwandani are made of iron sheets and tin as walls with iron roofing sheets. Houses are built in rows with an average of 


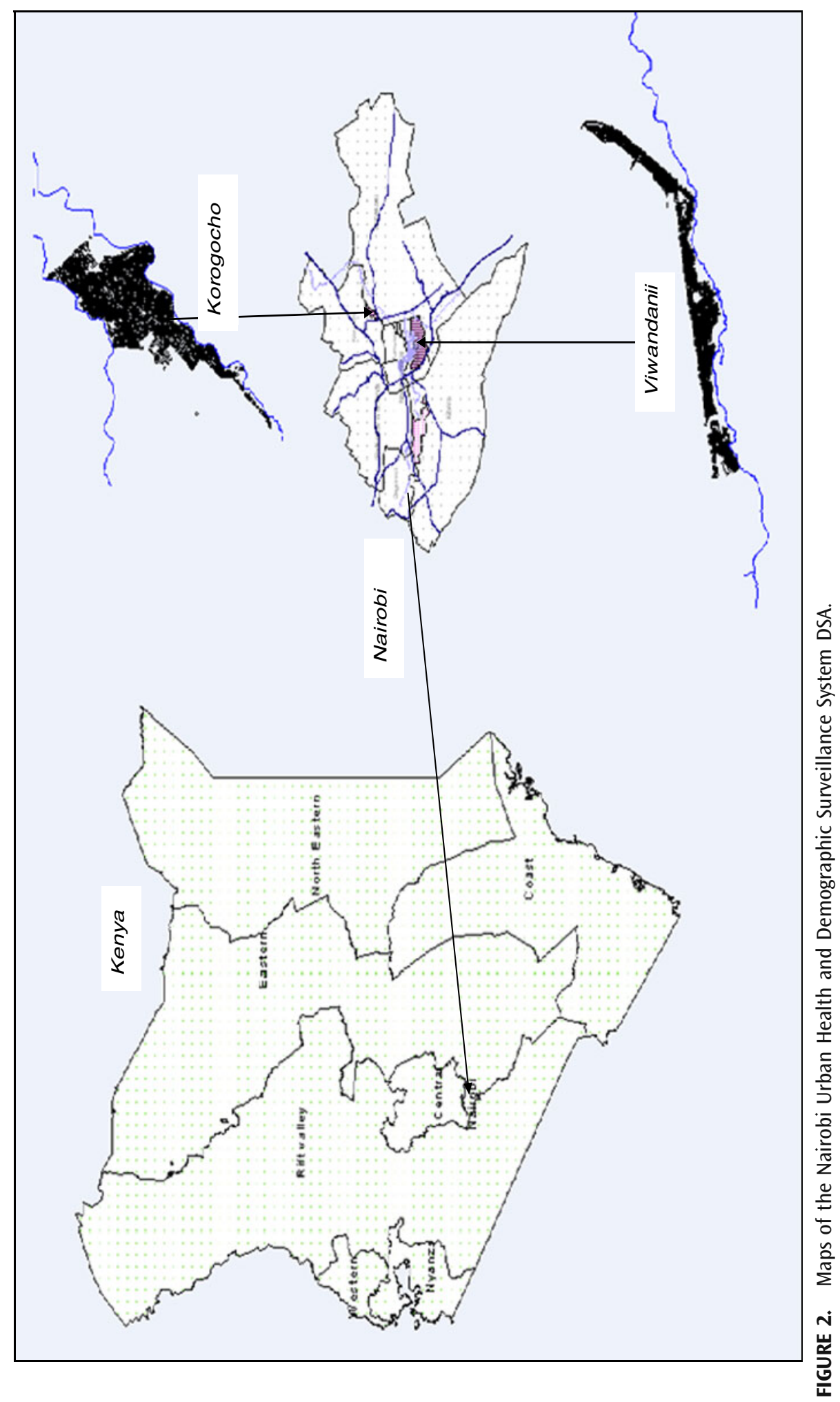


six dwelling units (rooms) per structure. The Ngong River, which is heavily polluted by industrial waste, is situated to the south of Viwandani and the industries are situated to the north of Viwandani.

The two slums are medium sized (in terms of population) among the numerous slum settlements in Nairobi and they represent some of the key distinguishing characteristics of slum communities in the city in terms of community and population stability. Korogocho represents a stable poor urban community with a more settled population since many of the residents have resided there for many years and about a quarter of its residents aged 12 and above was born in the community. Viwandani, on the other hand, represents a more transient community which attracts a youthful and highly mobile population seeking job opportunities in the nearby industries. Only 5 percent of Viwandani residents aged 12 and above reported having been born in the community. As shown by the demographic indicators in this paper (see Tables 2, 3 and 4) and others in this issue, the two areas exhibit remarkably different demographic, economic, and health outcomes, thereby underscoring the danger of treating slum settlements as uniform entities.

The NUHDSS's relational database is managed using SQL Server (back-end) and Visual Basic (front-end). After data entry, the HDSS manager exports data from SQL Server to STATA or SPSS software package for secondary cleaning. This step includes checking the completeness of the data, identifying unexpected or out-ofrange values, and documenting the data. Other operations such as basic analysis and merging files are also implemented during the secondary data cleaning. The approved cleaned analytical files are posted on the server for analysis by the center's researchers and its partners. In order to ensure good data quality, the NUHDSS has developed various quality control measures throughout data collection and processing, including the development of data quality monitoring tools and deploying of qualified, experienced, and regularly trained staff.

The following strategies are used to monitor and preserve data quality standards during data collection:

1. Retraining the fieldworkers at the beginning of each data collection round

2. Production of fieldworkers' performance and bias statistics

3. Fieldworkers and their team leaders edit $100 \%$ of the forms whereas field supervisors and the NUHDSS field coordinator respectively edit $5 \%$ of the forms edited at the next lower level

4. Fieldworkers do not work in the same households that they ever worked in until after one year from their last visit to those households

5. Team leaders and quality control officers organize spot checks of preselected households covered by each fieldworker

6. The use of amendment/update forms allows the reporting of corrections to mistakes that were made in previous rounds and the updating of timevariant characteristics such as number of people living in the household and marital status. In addition, the use of event confirmation forms permits the cross-checking of the accuracy of information from other forms.

At the data processing and management levels, the following procedures are used to monitor and ensure data quality standards:

1. Software and computer validation programs that allow for checking the logical consistency of data 
2. Close supervision of Data Entry Clerks (DECs; about one supervisor for three DECs) and calculation of the DECs's performance indicators at the end of each round

3. Retraining of DECs every round on new questionnaires and on how to use validation tools and detect errors and inconsistencies

4. Double entry of data on $5 \%$ of all questionnaires

5. Analysis of indicators in comparison with those derived from other data sources, analysis of the completeness of information, and identification of outliers during data cleaning.

\section{Key NUHDSS Challenges}

APHRC has faced a number of challenges in implementing the NUHDSS:

1. The first and most critical relates to the monitoring of internal movements of residents, given the informal nature of housing and living arrangements. Some people do not want to be tracked down when they move and may give incorrect information about their identity, limiting the capacity to link them to the previous identification number.

2. The repetitive nature of the HDSS exercise leads to respondent fatigue: interviewing residents there three times a year for so many years causes fatigue among respondents who may not see any direct benefits of the research in their lives. Also, there is considerable frustration, which sometimes gets vented on the field team, when dealing with a population with poor livelihood opportunities.

3. Security is poorer in the two communities than in non-slum areas. This has an impact on the ability of fieldworkers to work during odd hours and in certain high-risk parts of the DSA.

4. The high mobility of residents implies that attrition is high, suggesting that appropriate measures have to be taken both at the data collection and data analysis levels to adequately monitor health and demographic indicators.

In order to help minimize the adverse effect of these challenges, the Center has strived to build confidence by organizing regular, free health camps for residents, providing advice and supplies to community initiatives, hiring field staff from within the communities who know the study area well and are trusted by local residents, and disseminating the research findings within the communities.

\section{KEY DEMOGRAPHIC, HEALTH, AND ECONOMIC INDICATORS}

In this section, we provide insights on the key demographic indicators produced through the NUHDSS between 2003 and 2009. It is worth noting that the annual trends depicted in the section could not have been produced in the absence of the NUHDSS, given the lack of vital registration data in this setting. The tables, where appropriate or available also include comparative national and subnational indicators based on the Kenya Demographic and Health Surveys (KDHS).

\section{Population Structure and Changes}

The NUHDSS followed an average population of about 71,000 people living in about 28,500 households every year between 2003 and 2009. Analysis of the population of the DSA by age shows that, on average, $31 \%$ of the total NUHDSS population is aged less 


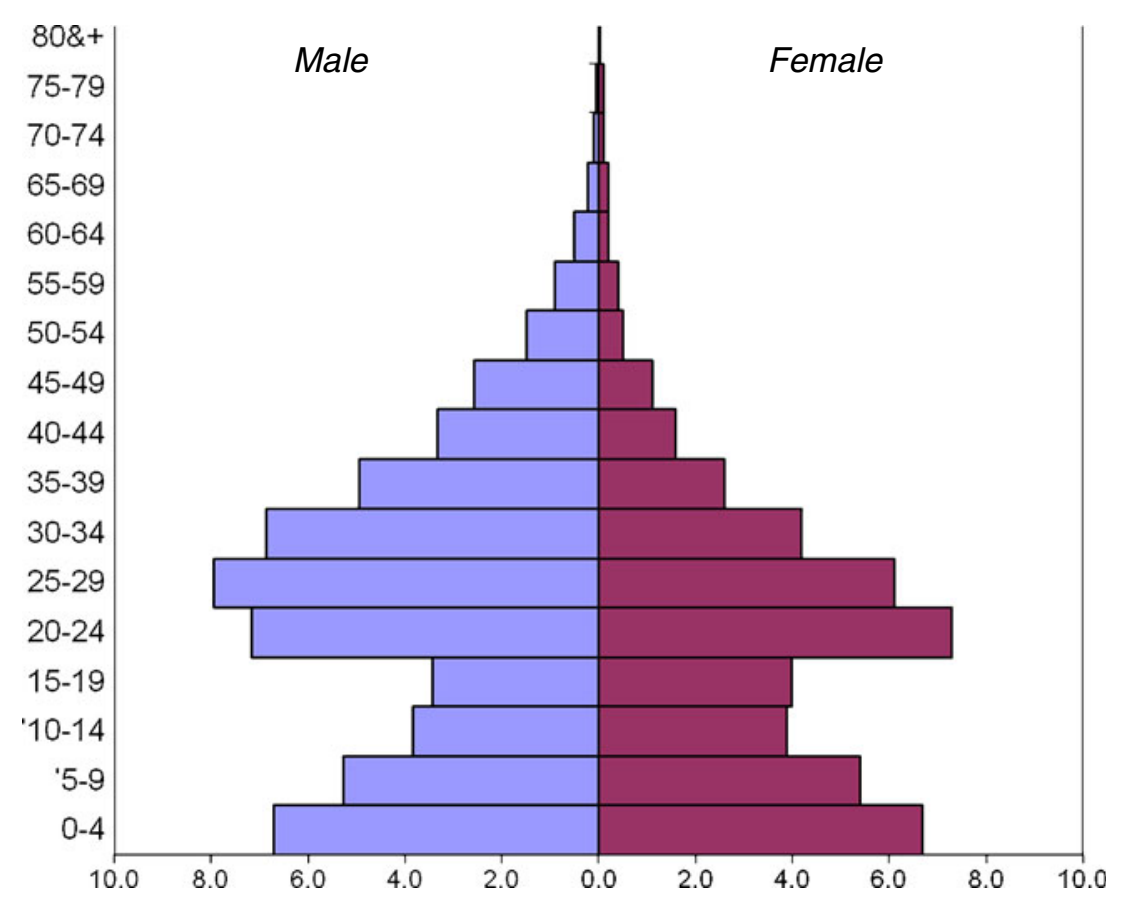

FIGURE 3. Population pyramid of the NUHDSS in 2009.

than 15 years, $68 \%$ is aged $15-64$ years, and 1\% is aged 65 years and above (Figure 3). There are location differences in population structure by age and by sex. Viwandani has more males aged 15-64 years than does Korogocho, while Korogocho has a slightly larger 0 to 4-year-old category. Likewise, Korogocho has a higher dependency ratio compared to Viwandani.

Relative to the whole of Nairobi, the NUHDSS population is predominantly male. In 2009, the sex ratio (including children) was 125 males to 100 females, but with striking differences by age group and between the two slum areas (Korogocho and Viwandani). Analysis by age and by slum area shows that sex ratio is higher among people aged 25 years and above, and in Viwandani (144 males to 100 females) compared to Korogocho (109 males to 100 females). Korogocho has a larger household size (3.0 people per household on average) compared to Viwandani (2.3 people per household).

Table 1 shows the NUHDSS population from 2003 to 2009 and the population as of January 1 of each year during the period. In general, the NUHDSS population increased by $16 \%$ from 67,204 people in 2003 to 78,156 residents in 2009. Population growth is slightly higher $(18 \%)$ in Viwandani compared to Korogocho $(14 \%)$. The marked difference between the number of people at the beginning of the year and the total that was monitored by the end of the year shows the extent of population mobility.

\section{Trends in Total Fertility Rate}

Table 2 presents trends in the total fertility rate (TFR) from 2003 to 2009. The TFR is a synthetic measure of fertility that gives the average number of births a woman would have by the time she reaches 50 years of age if she were to give birth at the current age-specific fertility rates. Unless otherwise specified, the TFR is for all women aged 15-49 years. The NUHDSS TFRs are based on 1 year while the Demographic and Health Surveys (DHS) covers the past 3 years. 
TABLE 1 The NUHDSS population, 2003-2009

\begin{tabular}{|c|c|c|c|c|c|c|}
\hline \multirow[b]{2}{*}{ Year } & \multicolumn{3}{|c|}{ Population monitored during the year } & \multicolumn{3}{|c|}{ Population on 1st January } \\
\hline & Korogocho & Viwandani & NUHDSS & Korogocho & Viwandani & NUHDSS \\
\hline 2003 & 29,708 & 37,496 & 67,204 & 23,328 & 26,105 & 49,433 \\
\hline 2004 & 32,469 & 40,739 & 73,208 & 25,373 & 30,009 & 55,382 \\
\hline 2005 & 32,329 & 35,994 & 68,323 & 26,409 & 26,673 & 53,082 \\
\hline 2006 & 32,690 & 36,987 & 69,677 & 26,877 & 28,563 & 55,440 \\
\hline 2007 & 32,186 & 38,998 & 71,184 & 26,996 & 30,163 & 57,159 \\
\hline 2008 & 31,904 & 41,182 & 73,086 & 25,741 & 31,605 & 57,346 \\
\hline 2009 & 33,880 & 44,276 & 78,156 & 26,277 & 34,392 & 60,669 \\
\hline Mean number & 32,167 & 39,382 & 71,548 & 25,857 & 29,644 & 55,502 \\
\hline $\begin{array}{l}\text { \% Change } \\
\quad 2003-2009\end{array}$ & $14.04 \%$ & $18.08 \%$ & $16.30 \%$ & $12.64 \%$ & $31.74 \%$ & $22.73 \%$ \\
\hline
\end{tabular}

Overall, fertility in the NUHDSS varied between 3.2 children per woman in 2003 and 3.8 per woman in 2004, with an average of 3.4 per woman over the study period. This level of fertility is higher than the TFR for Nairobi, but lower than the national level (4.9 children per woman in 2003 and 4.6 children per woman in 2008). Fertility in Korogocho is about half a child higher than that in Viwandani. Analysis of trends over time shows that fertility has remained constant over the 7-year period and is probably consistent with the general stall observed in Nairobi since the mid-1990's. ${ }^{11,12}$

\section{Trends in Child Mortality Indicators}

Child mortality indicators are a useful gauge of a country's level of health or development, and are components of the physical quality of life index. One of the targets of Millennium Development Goal \#4 seeks to reduce under-5-year-old mortality rates (U5M) by two thirds between 1990 and 2015. Table 3 shows trends in infant (under 1 year old) and U5M in the NUHDSS during the period 2003-2009.

Infant mortality rate (IMR), the probability of dying before the first birthday per 1,000 live births, has steadily declined between 2003 (82.3) and 2009 (58.5). This trend in infant mortality is consistent with data from the last two Kenya DHSs, which showed that the national IMR decreased from 75.5 in 2003 to 59.6 in 2008. The IMR is lower in Viwandani compared to Korogocho.

$\mathrm{U} 5 \mathrm{M}$ refers to the probability of dying between birth and the fifth birthday per 1,000 live births. U5M is always higher in Korogocho than in Viwandani. Overall, U5M has declined from 113 in 2003 to 79 in 2009. The rates in the two slum settlements are higher than those for any of the other population sub-groups. The trends observed in the DSA are also consistent with the national trends in Kenya.

TABLE 2 Total fertility rates by selected background characteristics, NUHDSS 2003-2009

\begin{tabular}{|c|c|c|c|c|c|c|c|}
\hline & 2003 & 2004 & 2005 & 2006 & 2007 & 2008 & 2009 \\
\hline Korogocho & 3.4 & 4.4 & 3.8 & 3.6 & 3.6 & 3.4 & 3.7 \\
\hline Viwandani & 2.9 & 3.3 & 3.2 & 3.4 & 3.2 & 3.3 & 3.2 \\
\hline Overall & 3.2 & 3.8 & 3.4 & 3.4 & 3.4 & 3.3 & 3.4 \\
\hline Nairobi (KDHS) & 2.7 & - & - & - & - & 2.8 & - \\
\hline Urban Kenya (KDHS) & 3.3 & - & - & - & - & 2.9 & - \\
\hline Kenya (KDHS) & 4.9 & - & - & - & - & 4.6 & - \\
\hline
\end{tabular}

KDHS Kenya Demographic and Health Surveys

Source: NUHDSS, http://www.statcompiler.com/tablebuilderController.cfm 
TABLE 3 Infant and under-5-year-old mortality by selected background characteristics, NUHDSS 2003-2009

\begin{tabular}{|c|c|c|c|c|c|c|c|}
\hline & 2003 & 2004 & 2005 & 2006 & 2007 & 2008 & 2009 \\
\hline \multicolumn{8}{|l|}{ Infant mortality } \\
\hline Korogocho & 108.9 & 91.1 & 86.9 & 77.7 & 79.4 & 75.6 & 73.1 \\
\hline Viwandani & 60.9 & 64.3 & 65.5 & 63.7 & 49.3 & 57.5 & 46.6 \\
\hline Overall & 82.3 & 78.4 & 76.4 & 70.4 & 63.7 & 65.5 & 58.5 \\
\hline Nairobi (DHS) & 75.5 & - & - & - & - & 59.6 & - \\
\hline Urban Kenya (KDHS) & 61.1 & - & - & - & - & 62.8 & - \\
\hline Kenya (KDHS) & 75.5 & - & - & - & - & 59.2 & - \\
\hline \multicolumn{8}{|l|}{ Under-5 mortality } \\
\hline Korogocho & 150.4 & 127.9 & 126.1 & 130.9 & 110.4 & 99.8 & 92.5 \\
\hline Viwandani & 80.0 & 82.8 & 87.2 & 87.1 & 67.1 & 75.0 & 67.5 \\
\hline Overall & 112.8 & 106.3 & 107.1 & 108.9 & 87.7 & 86.2 & 78.7 \\
\hline Nairobi (DHS) & 94.7 & - & - & - & - & 63.5 & - \\
\hline Urban Kenya (KDHS) & 93.5 & - & - & - & - & 74.5 & - \\
\hline Kenya (KDHS) & 112.7 & - & - & - & - & 83.7 & - \\
\hline
\end{tabular}

KDHS Kenya Demographic and Health Surveys

Sources: NUHDSS, Kenya, http://www.statcompiler.com/tablebuilderController.cfm

For instance, the U5M for Nairobi declined by 33\%, from 95 in 2003 to 64 in 2008-2009. The NUHDSS U5M also declined by 30\% during the same period ${ }^{13}$.

\section{Migration Trends}

One key feature of the longitudinal NUHDSS is its capacity to understand in-migration as well as out-migration patterns and determinants. We use the routine NUHDSS migration data and the migration and employment histories collected from 12,638 randomly selected participants aged 12 years and above in 2006 to describe characteristics of migrants.

(a) Place of birth for the NUHDSS residents

Table 4 shows the percentage of migrants and non-migrants (those born in the study communities) in the two slum communities, Korogocho and Viwandani, using the 2006 survey data. The majority of individuals are migrants, with the proportion of migrants being higher in Viwandani (95\%) than it is in Korogocho (75\%). The gender differences in place of birth are very minor.

For the migrants to the study communities, the vast majority were born in rural areas $-88 \%$ of males and $91 \%$ of females in Korogocho, and $92 \%$ of males and $96 \%$ of females in Viwandani.

(b) Place of origin and age at arrival

Table 5 presents the place of residence for in-migrants just before they moved into the DSA. The majority of migrants were living in rural places before migrating to the DSA ( $63 \%$ of females and $58 \%$ of males). The pattern is similar in both areas. Nevertheless, considerable intraurban mobility is also observed-over a third of male and female migrants came from other parts of Nairobi and at least $20 \%$ of male and female migrants migrated directly from a non-slum part of Nairobi.

Most people in-migrate into the slums when they were in their young adult age for both males and females. In Korogocho, about 22\% females and 13\% males moved into the slum when aged 15-19 years, while in Viwandani the corresponding percentages were $24 \%$ and $14 \%$, respectively. The percentage of migrants increases up to a peak at 20-29 years old for both slums and for both males and females.

(c) Duration of stay in the slum communities 
TABLE 4 Proportion of migrants and non-migrants in Korogocho and Viwandani

\begin{tabular}{|c|c|c|c|c|c|c|c|c|c|}
\hline \multirow[b]{2}{*}{ Migratory status } & \multicolumn{3}{|c|}{ Korogocho } & \multicolumn{3}{|c|}{ Viwandani } & \multicolumn{3}{|c|}{ Both Sites } \\
\hline & Female & Male & Total & Female & Male & Total & Female & Male & Total \\
\hline Non migrant & 26.4 & 23.5 & 24.8 & 5.9 & 4.8 & 5.2 & 15.6 & 12.3 & 13.7 \\
\hline Migrant & 73.6 & 76.5 & 75.2 & 94.1 & 95.2 & 94.8 & 84.4 & 87.7 & 86.3 \\
\hline Total & 100.0 & 100.0 & 100.0 & 100.0 & 100.0 & 100.0 & 100.0 & 100.0 & 100.0 \\
\hline $\mathrm{N}$ & 2,714 & 3,299 & 6,013 & 2,497 & 4,127 & 6,624 & 5,169 & 7,468 & 12,637 \\
\hline
\end{tabular}

Source: Nairobi Urban Health Demographic Surveillance System-nested migration and employment histories Survey, 2006

We use the 2006 survey data to examine duration of stay of people who are currently resident in the slum settlements. Migrants in Korogocho stay longer than do those in Viwandani (Tables 5 and 6). Residents in Korogocho have lived in the community for a cumulated average of about 14 years, while those in Viwandani have lived there for about 8 years. This statistics confirms the high mobility in Viwandani as opposed to the relative stability of the population in Korogocho. In both slum communities, males stay longer on average than females do. Other analyses have shown, however, that female migration is more intense than male migration. ${ }^{14}$ Contrary to conventional thinking about the lack of permanence of residence in slum settlements, these data show that slums provide long-term homes for many people. In Korogocho, $57 \%$ of women and $63 \%$ of men had lived in the slums for more than 10 years, while in Viwandani the corresponding figures were $25 \%$ and $36 \%$, respectively. Caution should be exercised in interpreting these durations because they are based on self-reported data of when people started living in these communities.

(d) In-migration and out-migration rates

The net migration rate is the difference between the in-migration and outmigration rates. A number of studies have shown that Nairobi is a net inmigration region. ${ }^{15-17}$ Table 7 presents the NUHDSS migration rates from 2003 to 2009, based on the routine NUHDSS migration data. Like in Nairobi, the NUHDSS migration difference (net migration) is positive. Between January 2003 and December 2009, on average, $27.1 \%$ of people moved into the DSA every year while about $25.6 \%$ moved out of the DSA. The average net annual migration rate for the study period is estimated at $1.1 \%$ during the period 2003-2009. The net migration magnitude varied between $-8.1 \%$ in 2004 to $5.5 \%$ in 2009 . The high out-migration rate observed in 2004 is due to the demolition exercise that affected

TABLE 5 Place of residence of migrants before moving into the DSA by gender

\begin{tabular}{|c|c|c|c|c|c|c|}
\hline \multirow[b]{2}{*}{ Place of residence } & \multicolumn{2}{|c|}{ Korogocho } & \multicolumn{2}{|c|}{ Viwandani } & \multicolumn{2}{|c|}{ Whole DSA } \\
\hline & Female & Male & Female & Male & Female & Male \\
\hline Non-DSA & 1.0 & 1.1 & 0.8 & 1.2 & 0.9 & 1.1 \\
\hline \multicolumn{7}{|l|}{ Korogocho/Viwandani } \\
\hline Other Nairobi slum & 12.5 & 12.2 & 8.5 & 11.0 & 10.3 & 11.5 \\
\hline Nairobi non-slum & 22.9 & 23.6 & 21.8 & 24.9 & 22.3 & 24.4 \\
\hline Other urban area of Kenya & 2.2 & 3.4 & 2.9 & 5.5 & 2.6 & 4.7 \\
\hline Rural Kenya & 60.3 & 58.8 & 65.9 & 57.4 & 63.4 & 57.9 \\
\hline Outside Kenya & 1.1 & 0.9 & 0.0 & 0.0 & 0.5 & 0.4 \\
\hline
\end{tabular}

Source: Nairobi Urban Health and Demographic Surveillance System - Nested migration and employment histories Survey, 2006. 
TABLE 6 Duration of stay in the slums of Nairobi for residents aged 12 years and above

\begin{tabular}{lll}
\hline & Korogocho & Viwandani \\
\hline Mean duration of stay & & \\
Females & 13.75 & 6.65 \\
Males & 14.42 & 8.15 \\
Overall & 14.13 & 7.59 \\
Proportions & & \\
Females & & 5.33 \\
Less than 1 year & 2.73 & 40.42 \\
$1-4$ years & 21.79 & 28.54 \\
5-9 years & 18.11 & 25.71 \\
More than 10 years & 57.37 & 2,607 \\
Total cases & 1,869 & \\
Males & & 3.41 \\
Less than 1 year & 1.72 & 31.23 \\
1-4 years & 18.42 & 29.16 \\
5-9 years & 16.42 & 36.2 \\
More than 10 years & 63.44 & 4,118 \\
Total & 2,222 & \\
\hline
\end{tabular}

Source: Nairobi Urban Health and Demographic Surveillance System - Nested migration and employment histories Survey, 2006.

households living near high-voltage electricity lines or near railway lines and pipelines. Residents were given a 3-month ultimatum to move out of their structures or face forced eviction and demolition of their houses. During that year, in-migration and out-migration rates reached $33.1 \%$ and $41.3 \%$, respectively. Although many structures were demolished and many residents were forced to leave the study area, many residents rebuilt their houses after they realized that the demolition notice was not seriously enforced. In general, in-migration and outmigration rates are higher in Viwandani than in Korogocho, corroborating the fact that the latter retains more of its population. For example in 2004, the in- and outmigration rates were $24 \%$ and $24 \%$ in Korogocho as compared to $42 \%$ and $58 \%$ in Viwandani, respectively.

\section{Poverty and Livelihood Status}

Given that livelihood prospects are the main attraction for people coming to Nairobi from rural areas (and ending up in slum settlements), it is important to examine

TABLE 7 Migration rates (\%) by selected background characteristics in the NUHDSS, 2003-2009

\begin{tabular}{|c|c|c|c|c|c|c|c|c|}
\hline Location & 2003 & 2004 & 2005 & 2006 & 2007 & 2008 & 2009 & Average \\
\hline \multicolumn{9}{|c|}{ In-migration rate } \\
\hline Korogocho & 20.0 & 24.4 & 21.6 & 21.2 & 19.1 & 23.3 & 28.1 & 22.5 \\
\hline Viwandani & 31.4 & 41.8 & 34.1 & 28.4 & 28.1 & 28.1 & 26.5 & 31.2 \\
\hline Overall & 26.1 & 33.1 & 28.0 & 25.0 & 24.0 & 26.0 & 27.2 & 27.1 \\
\hline \multicolumn{9}{|c|}{ Out-migration rate } \\
\hline Korogocho & 17.8 & 24.3 & 21.3 & 21.8 & 25.2 & 22.8 & 22.5 & 22.2 \\
\hline Viwandani & 27.2 & 58.0 & 28.9 & 24.4 & 25.1 & 21.6 & 21.1 & 29.5 \\
\hline Overall & 22.9 & 41.3 & 25.2 & 23.2 & 25.1 & 22.1 & 21.7 & 25.9 \\
\hline \multicolumn{9}{|c|}{ Net migration rate } \\
\hline Korogocho & 2.3 & 0.1 & 0.2 & -0.7 & -6.1 & 0.5 & 5.7 & 0.3 \\
\hline Viwandani & 4.1 & -16.2 & 5.2 & 4.0 & 3.0 & 6.5 & 5.4 & 1.7 \\
\hline Overall & 3.3 & -8.1 & 2.8 & 1.8 & -1.1 & 3.9 & 5.5 & 1.1 \\
\hline
\end{tabular}


what sort of income-generating activities slum residents rely on for their survival. Table 8 presents the economic activity status of residents aged 18 years and above over the last 30 days in 2009. Overall, among people aged 18 years and above, only $24 \%$ were involved in a salaried employment of established or stable business, with Korogocho residents being less likely to be in these two relatively stable income generating activities than their counterparts in Viwandani (16\% \% vs. 30\%). For the two slums combined, about half of men and women relied on the two unstable forms of income generation (unestablished business of casual employment) while $27 \%$ were economically inactive. About $59 \%$ of men were in these unstable livelihood sources while $9 \%$ were economically inactive. For women, however, half were economically inactive while $33 \%$ were in the two unstable sources of income. So, while many people migrate to Nairobi to look for better livelihood opportunities, most slum residents rely on unstable forms of income. It would be interesting to examine the extent to which migrants transition from the unstable to stable forms of income over time and how these transitions affect future migration decisions.

The NUHDSS data show an acute lack of basic amenities in slum settlements, although some improvement has been recorded over time. For example, the proportion of households with electricity increased from $32 \%$ to $40 \%$ between 2006 and 2008 (Table 9). The remainder households rely on kerosene for lighting. In 2006, about $6 \%$ of households had access to piped water in their homes. This proportion has decreased over time. The vast majority of households (over $90 \%$ ) buy water from vendors/kiosks where they pay exorbitant prices for water that is often contaminated by refuge and sewer ${ }^{18}$. From 2006 to 2009, the majority of households had pit latrines shared with other households; about 3\% in 2006 and $1 \%$ of households in 2009 had private toilets. Most areas of the informal settlements continue to suffer from incredible amounts of litter and waste in open areas and proper garbage disposal remains a huge challenge. In fact, the majority of households either dispose of garbage in public open spaces or in the river $169 \%$ in 2006 and $75 \%$ in 2009). The remainder of households reports relying on garbage disposal services, pits or dump sites. The vast majority of households (more than $80 \%$ from 2006 to 2009 ) report using kerosene as cooking fuel.

TABLE 8 Income generating activity (\%) status of population aged 18 years and above in 2009

\begin{tabular}{|c|c|c|c|c|c|c|c|c|c|}
\hline \multirow{2}{*}{$\begin{array}{l}\text { Economic } \\
\text { Activity status }\end{array}$} & \multicolumn{3}{|c|}{ Whole DSA } & \multicolumn{3}{|c|}{ Korogocho } & \multicolumn{3}{|c|}{ Viwandani } \\
\hline & Female & Male & Total & Female & Male & Total & Female & Male & Total \\
\hline $\begin{array}{l}\text { Sa1aried } \\
\text { Employment }\end{array}$ & 3.6 & 22.3 & 14.4 & 1.8 & 5.1 & 3.6 & 5.1 & 32.6 & 21.6 \\
\hline $\begin{array}{c}\text { Established } \\
\text { Business }\end{array}$ & 11.0 & 9.1 & 9.9 & 12.1 & 12.4 & 12.2 & 10.2 & 7.2 & 8.4 \\
\hline $\begin{array}{l}\text { Unestablished } \\
\text { Business }\end{array}$ & 13.0 & 9.1 & 10.7 & 15.1 & 13.2 & 14.1 & 11.4 & 6.6 & 8.5 \\
\hline $\begin{array}{l}\text { Casual } \\
\text { Employment }\end{array}$ & 21.4 & 49.8 & 37.8 & 18.6 & 54.9 & 38.1 & 23.5 & 46.8 & 37.5 \\
\hline $\begin{array}{l}\text { Economically } \\
\text { Inactive }\end{array}$ & 50.5 & 9.3 & 26.8 & 51.4 & 13.6 & 31.2 & 49.8 & 6.8 & 23.9 \\
\hline $\begin{array}{l}\text { Activity } \\
\quad \text { unspecified }\end{array}$ & 0.5 & 0.3 & 0.4 & 1.0 & 0.8 & 0.9 & 0.0 & 0.1 & 0.1 \\
\hline Total & 100.0 & 100.0 & 100.0 & 100.0 & 100.0 & 100.0 & 100.0 & 100.0 & 100.0 \\
\hline $\mathrm{N}$ & 14,686 & 19,887 & 34,573 & 6,433 & 7,415 & 13,848 & 8,253 & 12,472 & 20,725 \\
\hline
\end{tabular}


TABLE 9 Trends in access to basic amenities in the NUHDSS area

\begin{tabular}{|c|c|c|c|c|}
\hline & \multicolumn{4}{|c|}{ Source of water } \\
\hline & 2006 & 2007 & 2008 & 2009 \\
\hline Piped Water Bought from Vendors/Kiosks & 92.3 & 90.6 & 90.9 & 94.8 \\
\hline Tanks & 1.5 & 5.7 & 5.1 & 4.1 \\
\hline Private taps & 6.1 & 3.6 & 4.0 & 1.1 \\
\hline \multirow[t]{3}{*}{ Other } & 0.1 & 0.1 & 0.0 & 0.1 \\
\hline & \multicolumn{4}{|c|}{ Lighting source } \\
\hline & 2006 & 2007 & 2008 & 2009 \\
\hline Kerosene & 67.4 & 78.3 & 59.3 & 62.4 \\
\hline Electricity & 32.1 & 21.2 & 40.3 & 37.3 \\
\hline \multirow[t]{3}{*}{ Other } & 0.5 & 0.5 & 0.4 & 0.2 \\
\hline & \multicolumn{4}{|c|}{ Cooking Fuel } \\
\hline & 2006 & 2007 & 2008 & 2009 \\
\hline Kerosene & 85.8 & 91.9 & 80.6 & 86.8 \\
\hline Electricity/gas & 1.8 & 0.7 & 0.8 & 1.3 \\
\hline \multirow[t]{3}{*}{ Other (charcoal, dung, briquettes, etc.) } & 12.5 & 7.4 & 18.5 & 11.9 \\
\hline & \multicolumn{4}{|c|}{ Type of toilet } \\
\hline & 2006 & 2007 & 2008 & 2009 \\
\hline Private toilet & 2.9 & 1.1 & 1.0 & 0.8 \\
\hline Shared toilet & 74.9 & 63.0 & 54.4 & 54.1 \\
\hline Flush trench toilets/toilets without working flush & 21.6 & 35.3 & 44.4 & 43.7 \\
\hline \multirow[t]{3}{*}{ No toilet } & 0.6 & 0.6 & 0.2 & 1.4 \\
\hline & \multicolumn{4}{|c|}{ Garbage disposal } \\
\hline & 2006 & 2007 & 2008 & 2009 \\
\hline Dump site/garbage services/pits & 30.6 & 27.1 & 23.9 & 25.1 \\
\hline No garbage disposal arrangement & 69.4 & 72.9 & 76.1 & 74.9 \\
\hline
\end{tabular}

One of the unique features of the NUHDSS data is that it allows assessment of transition in-and-out of poverty for households that were there at two points in time as shown below in Table 10. Overall, there was a reduction in the poverty headcount for all households in 2006 and 2009; the proportion of households below the poverty line (estimated at 2913 Kenyan Shillings) declined from 55\% in 2006 to 35\% in 2009. Tracking of same households shows that there was greater transition from being poor to non-poor $(47 \%)$ than there was from being non-poor to poor $(30 \%)$. This reduction in absolute poverty is in line with the observed decline between 2003 and $2006^{19}$ as well as the improvements in amenities described in this study.

\section{CONCLUSION}

Health and demographic surveillance systems have been set up to fill an evidence gap that has resulted from lack of vital registration systems in Africa. The Nairobi Urban HDSS was set up to provide a platform for investigating linkages between urban poverty, health and demographic outcomes, and to facilitate the evaluation of interventions to improve the wellbeing of the urban poor. The Nairobi HDSS has shown that it is feasible to set up and implement a long-term demographic surveillance system in urban slum settlements. Given the growing importance of slum settlements and longitudinal research platform in Africa's major cities and other urban areas, such comprehensive and time-series data are vital for guiding policy and program actions aimed at improving the wellbeing of the urban poor.

The findings presented in this paper not only confirm the high level of population mobility in slum settlements, but also demonstrate that slum settlements 
TABLE 10 Poverty status and poverty transitions in the NUHDSS area, 2003-2009

\begin{tabular}{llll}
\hline & \multicolumn{2}{l}{ Poverty status } & \\
\cline { 2 - 4 } & 2006 & 2009 & - \\
\hline Below poverty line & 55.2 & 34.7 & - \\
Above poverty line & 44.8 & 65.3 & - \\
Total & 100.0 & 100.0 & Total \\
& Poverty transition between 2006 and 2009 & 100.0 \\
Below poverty line 2006 & Below poverty line 2009 & Above poverty line 2009 & 100.0 \\
Above poverty line 2006 & 53.2 & 46.8 & 69.8 \\
\hline
\end{tabular}

are long-term homes for many people. Researchers and policy makers should take account of this duality in the characteristics of the slum population when designing their research and intervention programs. For instance, in order to effectively evaluate long-term interventions, researchers and policy makers might need to target long-term residents. Researchers who want to monitor a population for long durations should also understand the characteristics of the population that is likely to be there for a long time.

The results have also shown substantial improvements in measures of child mortality, while there has been limited decline in fertility in slum settlements. These trends are consistent with those observed from national survey data such as the DHSs for Nairobi and other parts of Kenya. There is need for further investigation to shed light on what is driving the mortality decline in these communities given that the immunizations levels are very $\operatorname{low}^{20}$ and the burden of disease for under-5-yearold children (which is mostly driven by diarrhea and pneumonia) remains very high. ${ }^{21}$ Other analyses of the NUHDSS data have shown a reduction in overall poverty levels and some improvement in living conditions as measured by household possessions and amenities. ${ }^{19}$ These improvements in the living conditions and socioeconomic status may be part of the explanation for the reductions in mortality.

\section{ACKNOWLEDGMENT}

We warmly acknowledge the generous support for the NUHDSS from the Rockefeller Foundation (USA), the Wellcome Trust (UK) and the William and Flora Hewlett Foundation (USA). We would like to thank those who contributed to the development and the management of the NUHDSS since its inception, especially Pierre Ngom and Zewdu Woubalem. We also acknowledge other colleagues for their contributions to the management of the NUHDSS's field operation and data systems: Eliud Wekesa, Harrison Njamba, Bonface Nganyi, Clement Oduor, and Peter Nyongesa. We are grateful to the data entry and management team, field teams, community leaders and residents whose continuous contribution and support has made possible the implementation and management of the NUHDSS.

OPEN ACCESS This article is distributed under the terms of the Creative Commons Attribution Noncommercial License which permits any noncommercial use, distribution, and reproduction in any medium, provided the original author(s) and source are credited. 


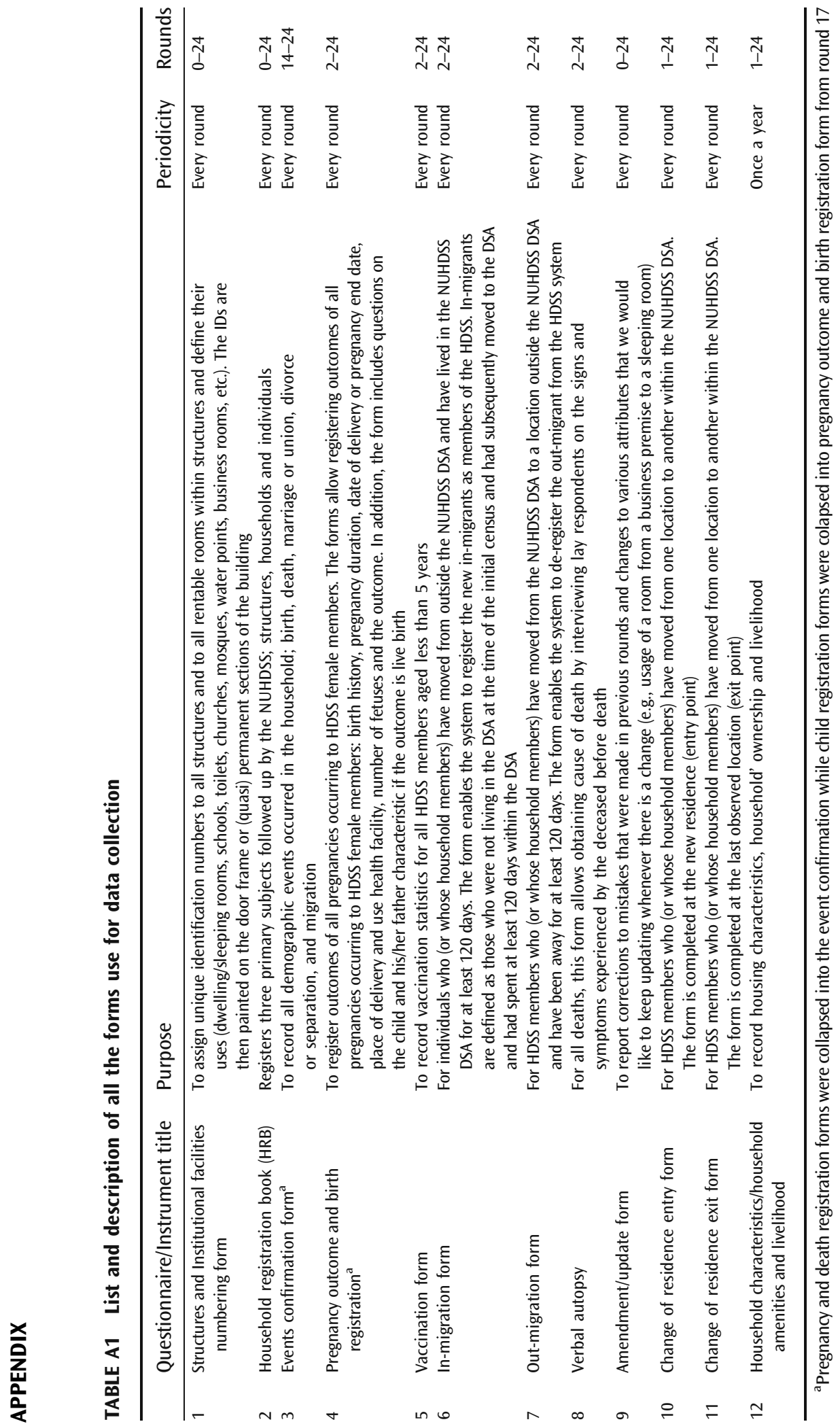




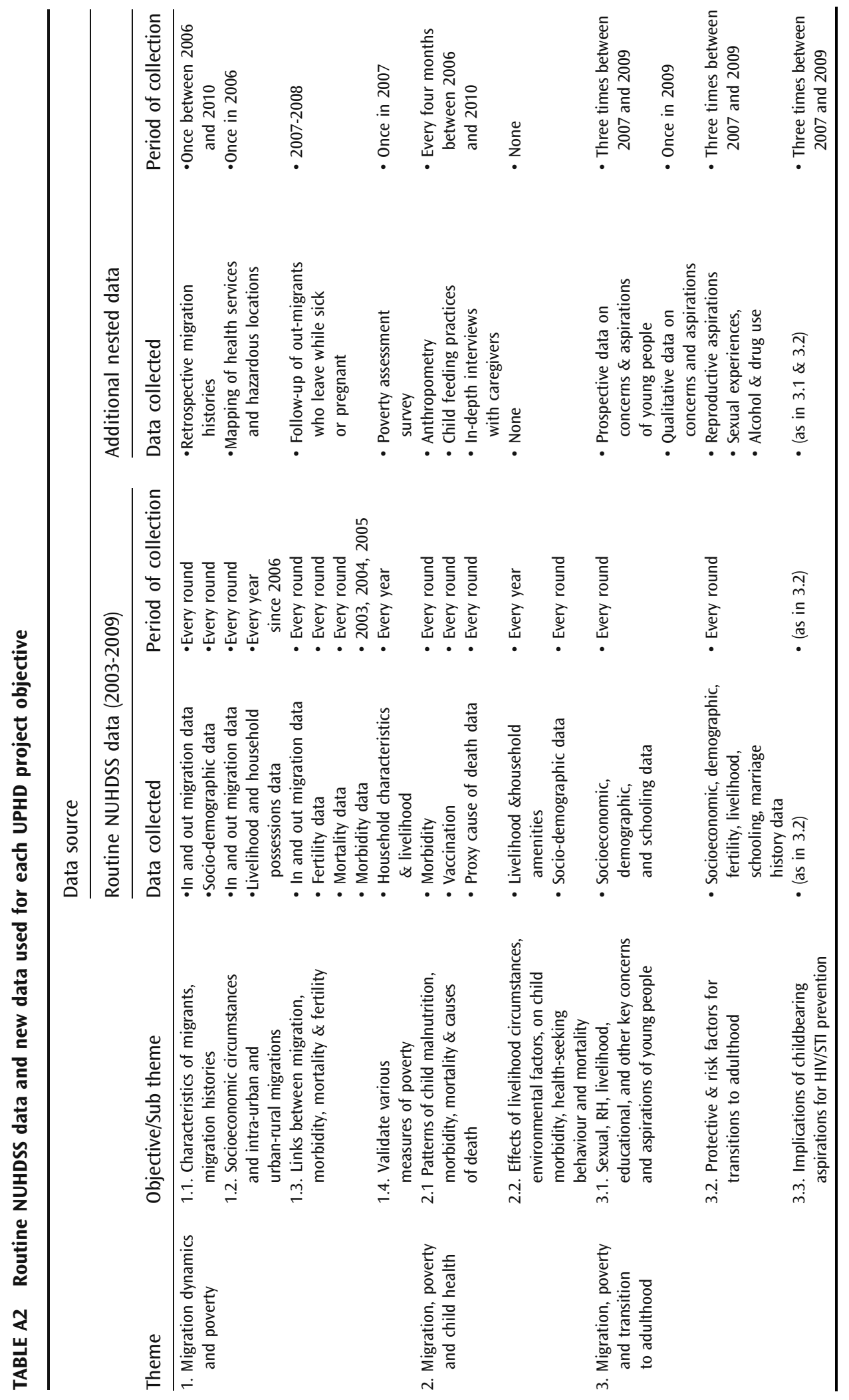




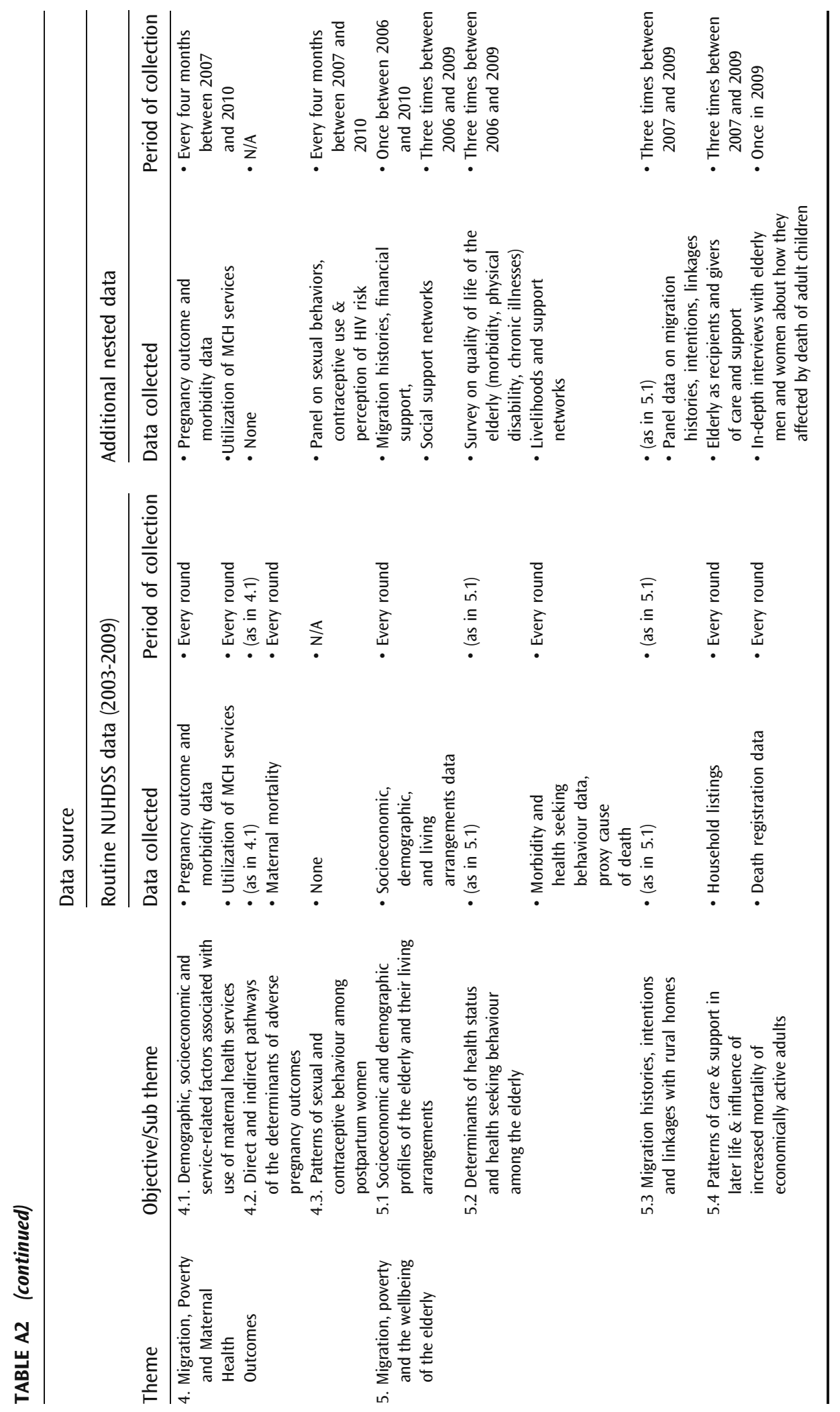




\section{REFERENCES}

1. INDEPTH Network. Population and Health in Developing Countries. Population, health and Survival at INDEPTH Sites. Ottawa, Canada: IDRC; 2002.

2. Tollman S, Kark SK, Kark E. The Pholela Health Centre: understanding health and disease in South Africa through community-oriented primary care (COPC). In: Gupta MD, Aaby P, Garenne M, Pison G, eds. Prospective Community Studies in Developing Countries. Oxford, England: Clarendon; 1997: 213-232.

3. Kark SL, Chesler J. Survival in infancy: a comparative study of stillbirths and infant mortality in certain Zulu and Hindu communities in Natal. S Aft J Lab Clin Med. 1956; 2 (2): 134-159.

4. Garenne M, Cantrelle P. Three decades of research on population and health: the ORSTOM experience in rural Senegal, 1962-1991. In: Gupta MD, Aaby P, Garenne M, Pison G, eds. Prospective Community Studies in Developing Countries. Oxford, England: Clarendon; 1997: 233-252.

5. Chandramohan D, Shibuya K, Setel P, et al. Should data from demographic surveillance systems be made more widely available to researchers? PLoS Med. 2008; 5(2): e57.

6. Savigny Dd, Kasale H, Mbuya C, Reid G. Fixing health systems. 2nd ed. Ottawa, Canada: IDRC; 2008.

7. International Centre for Diarrhoeal Diseases Research Bangladesh -ICDDR B. Health and Demographic Surveillance System-Matlab. Registration of Health and Demographic Events 2008. Dhaka, Bangladesh: ICDDR, B; 2010.

8. Binka FN, Nazzar A, Phillips JF. The Navrongo Community Health and Family Planning Project. Stud Fam Plann. 1995; 26(3): 121-139.

9. World Urbanization prospects: The 2009 Revision. 2009. http://esa.un.org/unpd/wup/ index.htm.

10. UN-Habitat. State of African Cities 2010. Governance, Inequalities and Urban Land Markets. UN-Habitat; 2010.

11. Ezeh AC, Mberu BU, Emina JO. Stall in fertility decline in Eastern African countries: regional analysis of patterns, determinants and implications. Philos transactions $R$ Soc B. 2009; 364(1532): 2991-3007.

12. Westoff CF, Cross AR. The Stall in the Fertility Transition in Kenya. Calverton, MD: ORC Macro; 2006.

13. Kenya National Bureau of Statistics (KNBS), ICF Macro. Kenya demographic and health survey 2008-09. Calverton: KNBS and ICF Macro; 2010.

14. Beguy D, Bocquier P, Zulu E. Circular migration patterns and determinants in Nairobi slum settlements. Demogr Res. 2010; 23(20): 549-586.

15. Society for International Development. Pulling Apart: Facts and Figures on Inequality in Kenya. Nairobi, Kenya: SID Eastern Africa Regional Office; 2004.

16. Society for International Development. Inequality in Kenya. Nairobi, Kenya: SID Eastern Africa Regional Office; 2006.

17. Oucho JO. Migration and regional development in Kenya. Development. 2007; 50(4): 88-93.

18. Mudege NN, Zulu EM. Discourses of Illegality and exclusion: when water access matters. Glob Public Health. 2011; 6(3): 221-233.

19. World Bank. Kenya poverty and inequality assessment (volume 1: synthesis report) - draft report. 2008. 44190-KE.

20. Mutua M, Kimani-Murage E. Childhood vaccination in informal urban settlements in Nairobi, Kenya: who gets vaccinated? BMC Public Health. 2011; 11(1): 6.

21. Kyobutungi C, Ziraba A, Ezeh AC, Yé Y. The burden of disease profile of residents of Nairobi's slums: Results from a Demographic Surveillance System. Popul Health Metr. 2008; 6:1. 